\title{
Altímetro Laser para a Missão Espacial Brasileira ASTER - ALR. Modelagens e Simulações para Criação do Software a Embarcar na Unidade de Controle e Processamento de Sinais do Instrumento.
}

\author{
A. G. V. de Brum ${ }^{1}$, F. C. da Cruz ${ }^{2}$, A. Hetem Jr ${ }^{1}$ \\ 1 CECS/Universidade Federal do ABC, S. André, SP, Brasil - antonio.brum@ufabc.edu.br \\ 2 Instituto de Física Gleb Wataghin, Universidade Estadual de Campinas, SP, Brasil - flavio@ifi.unicamp.br
}

\begin{abstract}
Resumo
Este trabalho está diretamente relacionado ao desenvolvimento do altímetro laser para a missão ASTER, denominado ALR. A primeira missão brasileira ao espaço profundo planeja enviar em 2017 uma nave para explorar o asteroide triplo 2001-SN263. O ALR será utilizado na investigação científica da forma, topografia e distribuição de massa dos componentes do asteroide triplo, que será realizada nas fases de maior proximidade. O instrumento desempenhará também papel importante como sensor auxiliar de navegação da nave. Coordenado pela UFABC, o desenvolvimento proposto envolve uma parceria entre a UFABC, UNICAMP e empresas do setor aeroespacial nacional. Este trabalho descreve as modelagens e simulações efetuadas para criação e testes do software que comporá a unidade de controle e processamento de sinais do instrumento. Como resultado principal, um ambiente de simulação da operação do aparelho foi criado e denominado $A L R \_$Sim. A simulação envolve as características: do aparelho (emissor e receptor) e do ambiente em que ele opera (meio e alvo: transmissividade, refletividade, rugosidade, ocorrência de falésia, superfícies inclinadas, etc.). Como saída da simulação, as formas de onda que se espera obter como sinal de retorno para diferentes formas de pulsos emitidos. O ALR_Sim foi testado com sucesso com relação às situações mais comuns esperadas.
\end{abstract}

Palavras chave: Missão Brasileira ao Espaço Profundo ASTER, Altímetro Laser - ALR, laser rangefinder, software de controle, ambiente simulador - ALR_Sim, asteroide 2001-SN263. 


\section{Introdução}

Dentre os instrumentos que voarão na $1^{\text {a }}$ missão espacial brasileira ASTER, o altímetro laser, denominado ALR (ASTER Laser Rangefinder), está em desenvolvimento sob coordenação de engenharia da UFABC e em parceria entre a UNICAMP, UFABC e empresas do setor aeroespacial (Figura 1). A descrição da missão bem como as características do instrumento são apresentadas nas referências [1, 2].

Instrumento crucial para a missão, o ALR contribuirá para a caracterização geodésica e geofísica dos componentes do asteroide triplo e também a navegação da nave fará uso da informação obtida pelo instrumento. O ALR fornecerá informação precisa da distância da nave até o alvo e da velocidade relativa entre ambos que será útil à navegação da nave nas fases de encontro e aproximação com o sistema (distância $<50 \mathrm{~km}$ ), principalmente nas fases de maior proximidade com cada um dos asteroides. Os dados do aparelho serão combinados com os dados das câmeras imageadoras para levantamento preciso das características topográficas dos alvos, com uso de estereofotoclinometria, técnica proposta por Gaskel em 2001 [3], aplicada com êxito na modelagem de corpos do sistema solar (como o asteroide EROS, missão NEAR-Shoemaker [4]).

Este trabalho descreve e apresenta uma parte do estudo realizado tendo em vista a criação do software para a Unidade de Controle e Processamento de Sinais do instrumento, UCPS (Figura 2). O estudo realizado resultou na modelagem do aparelho (transmissor e receptor), do ambiente de operação deste e do alvo. Um pacote simulador da operação do aparelho foi criado para oferecer como saída a forma de onda detectada (tempo X potência) e registrada pelo aparelho como sinal de retorno relativo à emissão de um pulso laser e sua reflexão no alvo.

O pacote simulador criado oferece ambiente apropriado à implementação e testes das rotinas que comporão o software de controle e processamento de sinais do instrumento real. Adicionalmente, os resultados das simulações oferecem informação importante para a definição dos componentes específicos adequados para composição do aparelho real, tendo em vista os objetivos do aparelho dentro da missão. As linhas diretrizes deste software são apresentadas.

Este estudo teve por objetivo a modelagem e simulação da operação de um aparelho altímetro laser com as características do ALR. A atividade empreendida englobou:

i. a emissão de pulsos laser de vários tipos (formas de onda);

ii. a amostragem e detecção do pulso emitido;

iii. a propagação no meio, as características do footprint (área iluminada pelo pulso na supefície do alvo) e a reflexão em alvos diferentes;

iv. a amostragem, detecção e processamento das formas de onda dos pulsos que retornam refletidos pelo alvo.

\section{Fundamentos para as Modelagens e Simulações}

O footprint, isto é, a área iluminada por um pulso laser que atinge a superfície de um alvo depende da distância $R$ entre o emissor e o alvo, da abertura (diâmetro) do feixe emitido $\left(\mathrm{d}_{\mathrm{ta}}\right)$ e do ângulo de dispersão do feixe $\theta_{t}$ (cone completo; $\theta_{t} / 2=$ meio cone). A Figura 3 mostra estes parâmetros.

A intensidade da luz que atinge o alvo depende também destes elementos, mas também depende da potência da luz emitida $\left(P_{t}\right)$ e da absorção que ocorre durante a propagação da luz no meio, dada por $\mathrm{M}(1 \geq \mathrm{M} \geq 0 ; \mathrm{M}=1$ para o vácuo). A referência [5] oferece base teórica para as modelagens descritas.

A intensidade da luz que retorna ao instrumento e é detectada por este (Figura 4) depende também dos elementos citados e depende ainda da característica de refletividade do alvo (refletância $\rho$; dependente do comprimento de onda da luz incidente; tomada a partir de [6]), do modelo de reflexão adotado (aqui: superfície lambertiana com refletividade difusa e, portanto, a intensidade da luz refletida depende da sua direção, sendo máxima na direção normal à superfície refletora) e da área de abertura do receptor/detector $\left(A_{r}\right)$. Adicionalmente, a intensidade detectada depende também do modelo de distribuição espacial da energia no footprint adotado. 

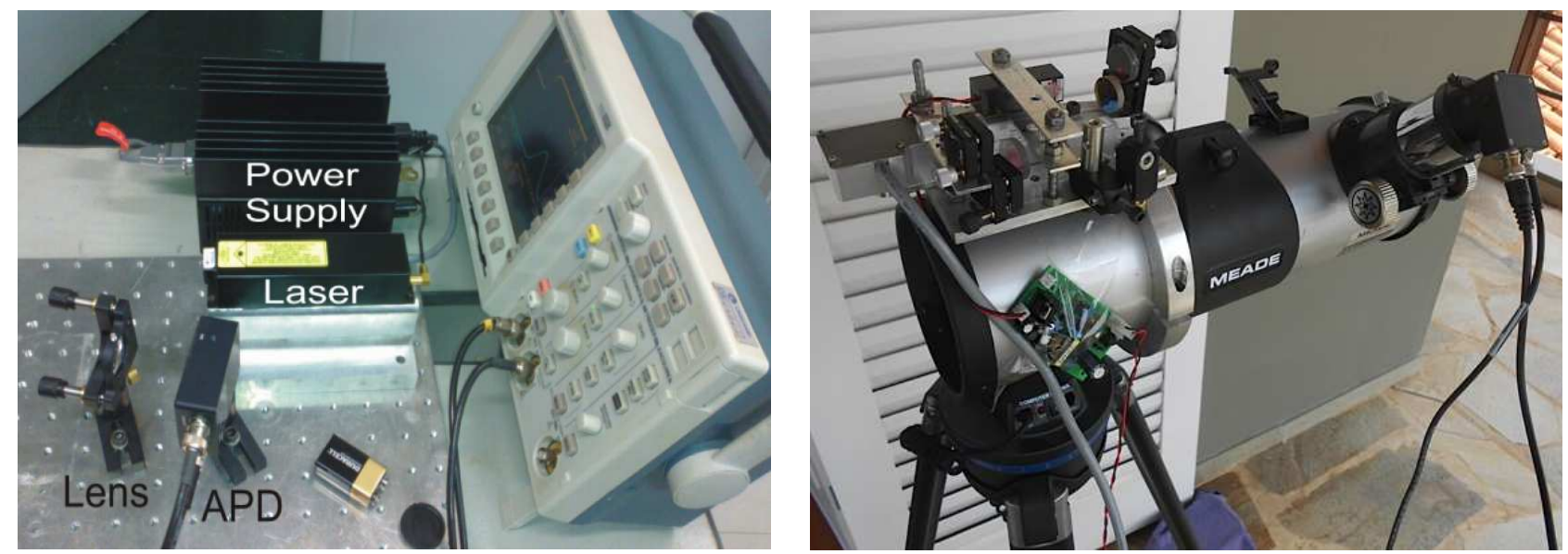

Figura 1 - Montagem preliminar do ALR. Esquerda: laser de microchip de Nd:YAG com fonte; direita: montagem em telescópio com detector de avalanche à direita (APD).

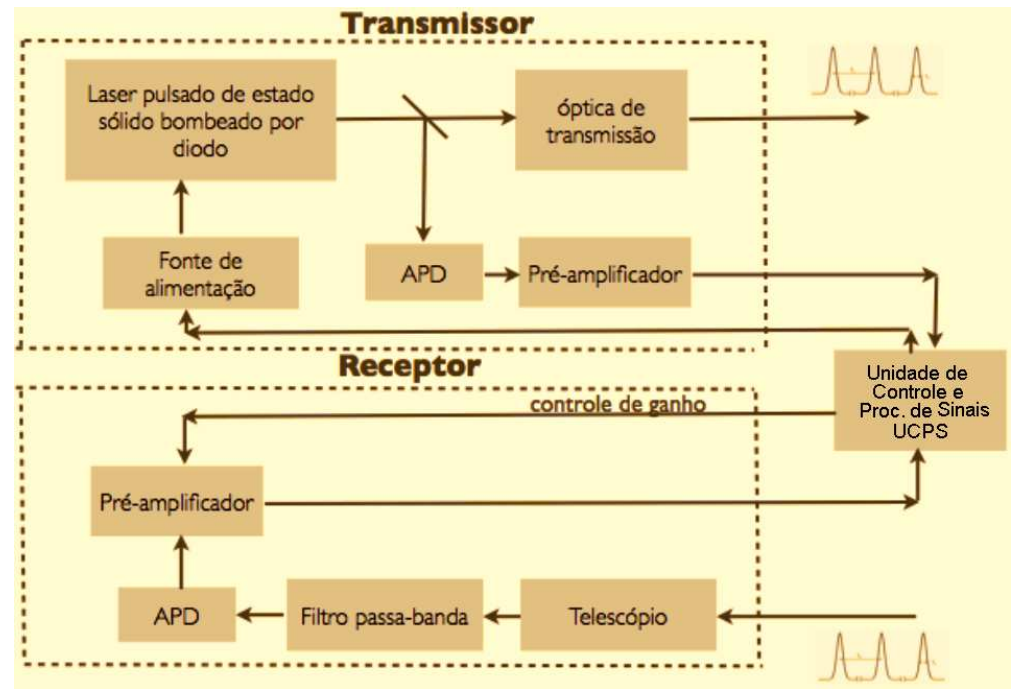

Figura 2 - Diagrama de blocos simplificado do projeto do ALR.

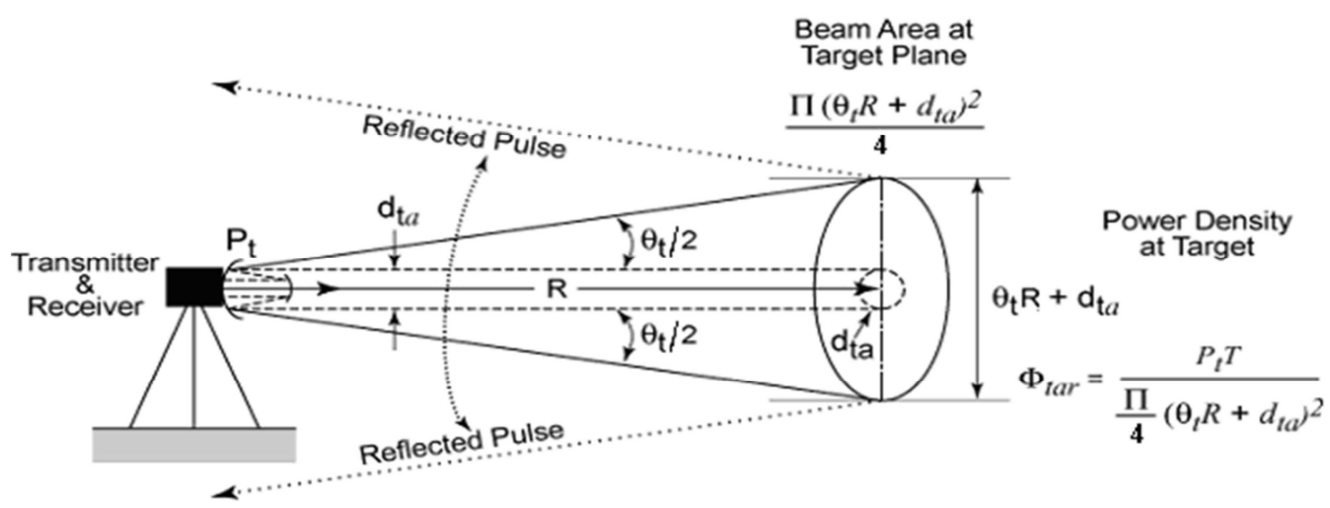

Figura 3 - Área iluminada pelo feixe incidente (footprint) e densidade de potência no alvo. FONTE: adaptação de [5], p. 22.

A distribuição espacial de energia de um laser depende das características do laser utilizado. Em geral, os perfis são modelados por uma distribuição cilíndrica (forma de "chapéu plano", que considera que a luz do pulso emitido atinge o alvo mantendo intensidade igual ao longo de todo o feixe cilíndrico), ou por uma distribuição 2D-simétrica Gaussiana [7]. Um exemplo típico de distribuição espacial de energia do tipo "chapéu plano" é mostrada na Figura 5. 


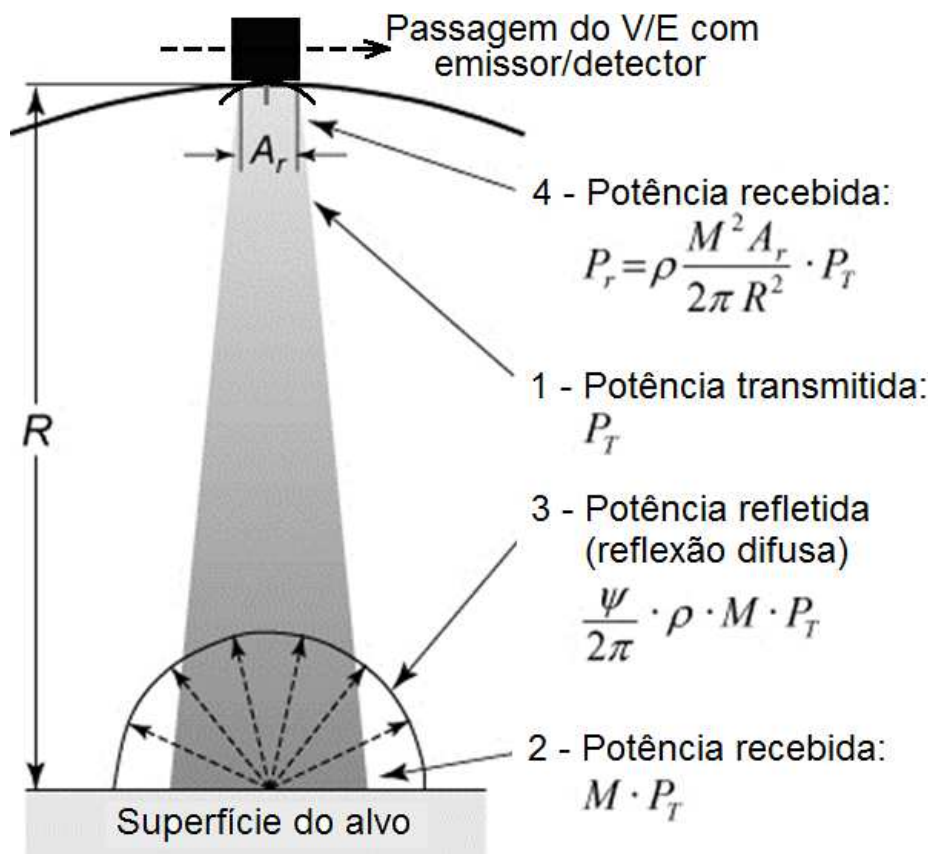

Figura 4 - A potência transmitida, refletida e recebida pelo detector (após reflexão) é mostrada no diagrama acima.

FONTE: Adaptado de [8].
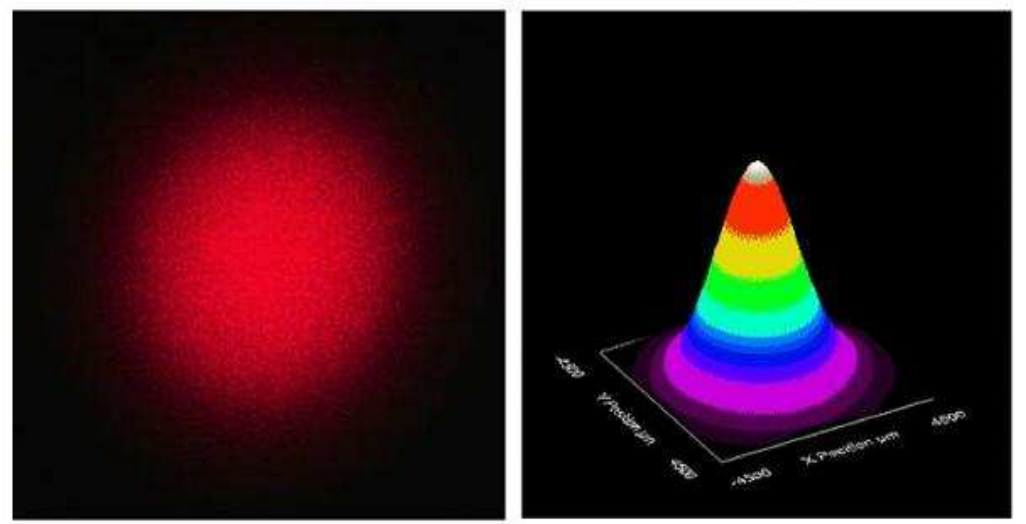

Figura 5 - (ao lado) Exemplo de distribuição espacial da energia de um laser com distribuição gaussiana (formato do feixe/seção transversal). FONTE: Odic Force Lasers (odicforce.com).

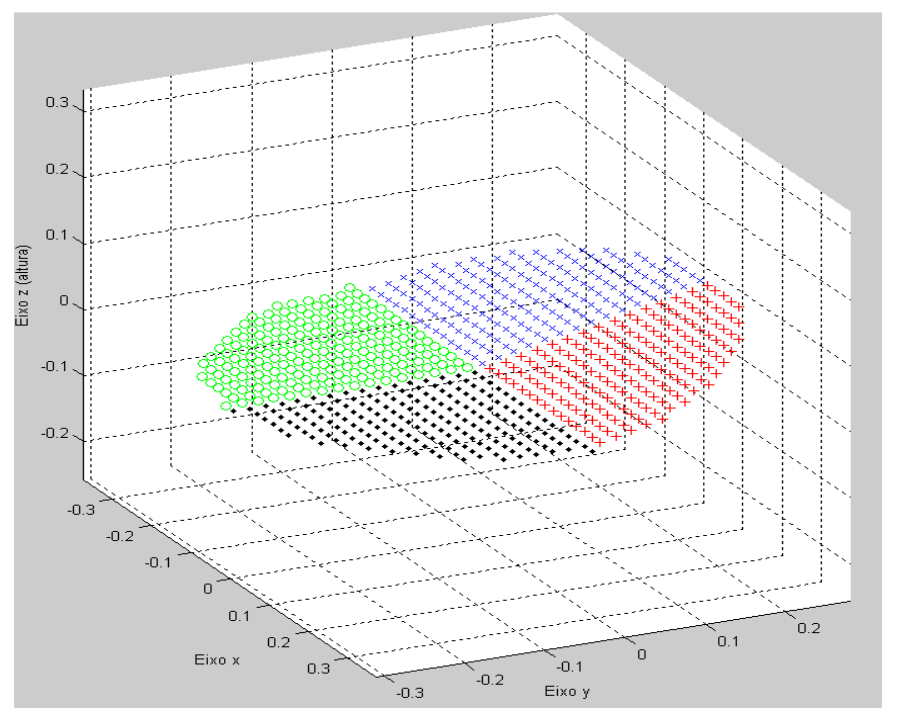

Figura 6 - Footprint modelado como 'N pequeninas fontes pontuais" de luz que refletem a energia absorvida pelo alvo de volta ao detector. A área total foi dividida em 4 quadrantes 
com características distintas de distância (altura), inclinação e refletância, que são ajustáveis na simulação. Aqui: declive de $10^{\circ}$ nos quadrantes 1 e 2 e $0^{\circ}$ de declive nos quadrantes 3 e 4.

\section{Modelo das "N pequeninas fontes pontuais"para a luz refletida pelo footprint}

A luz refletida foi tratada da seguinte maneira: a área total iluminada foi dividida em $\mathrm{N}$ subáreas de tamanho $\mathrm{dL}^{2}$ (escolhe-se $\mathrm{dL}=1 \mathrm{~cm}$, por exemplo). O número $\mathrm{N}$ de elementos de área é calculado e armazenado assim como a posição do centro de cada um desses elementos, $P_{i}=\left(x_{i}, y_{i}, 0\right), i=1,2$, .., N. Tem-se, assim, $\mathrm{N}$ subáreas entre as quais a energia total refletida é dividida igualmente (em uma primeira abordagem). Um exemplo desta abordagem é apresentado na Figura 6, onde se considera também a inclinação do terreno, com a posição de cada fonte dada por $P_{i}^{\prime}=\left(x_{i}^{\prime}, y_{i}^{\prime}, z_{i}^{\prime}\right)$, $\mathrm{i}=1,2, . ., \mathrm{N}$.

\section{Resultados}

Como resultado principal, um simulador da operação de um altímetro laser foi criado com auxílio do MATLAB, o ALR_Sim. As imagens a seguir foram obtidas em simulação com seu uso.

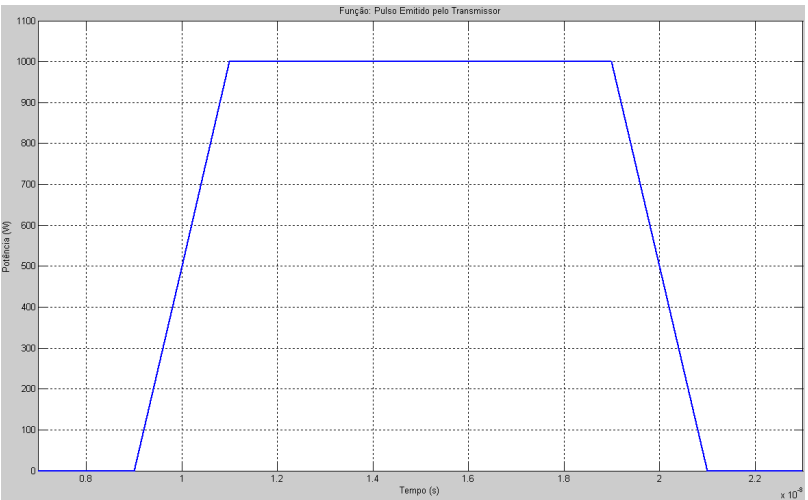

Figura 7 - Modelo trapezoidal suposto para o pulso emitido (uma possibilidade).

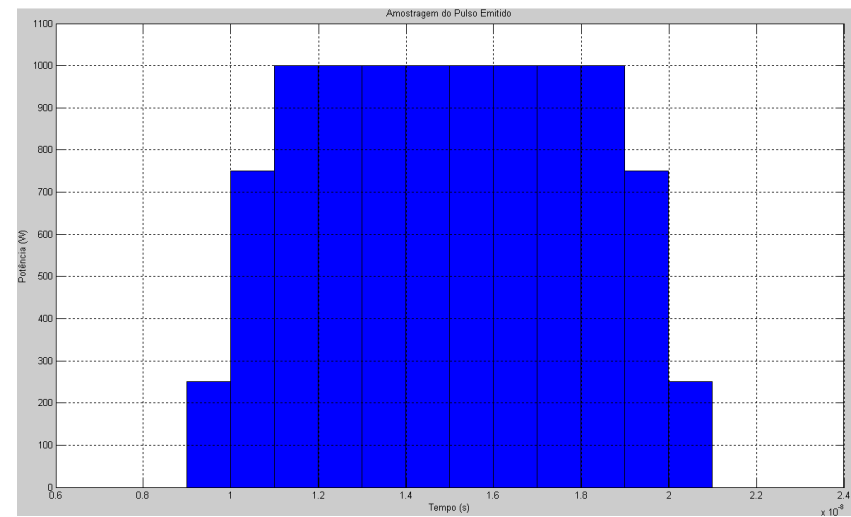

Figura 8 - Amostragem do pulso emitido trapezoidal a intervalos $\mathrm{dt}=1 \mathrm{~ns}$.

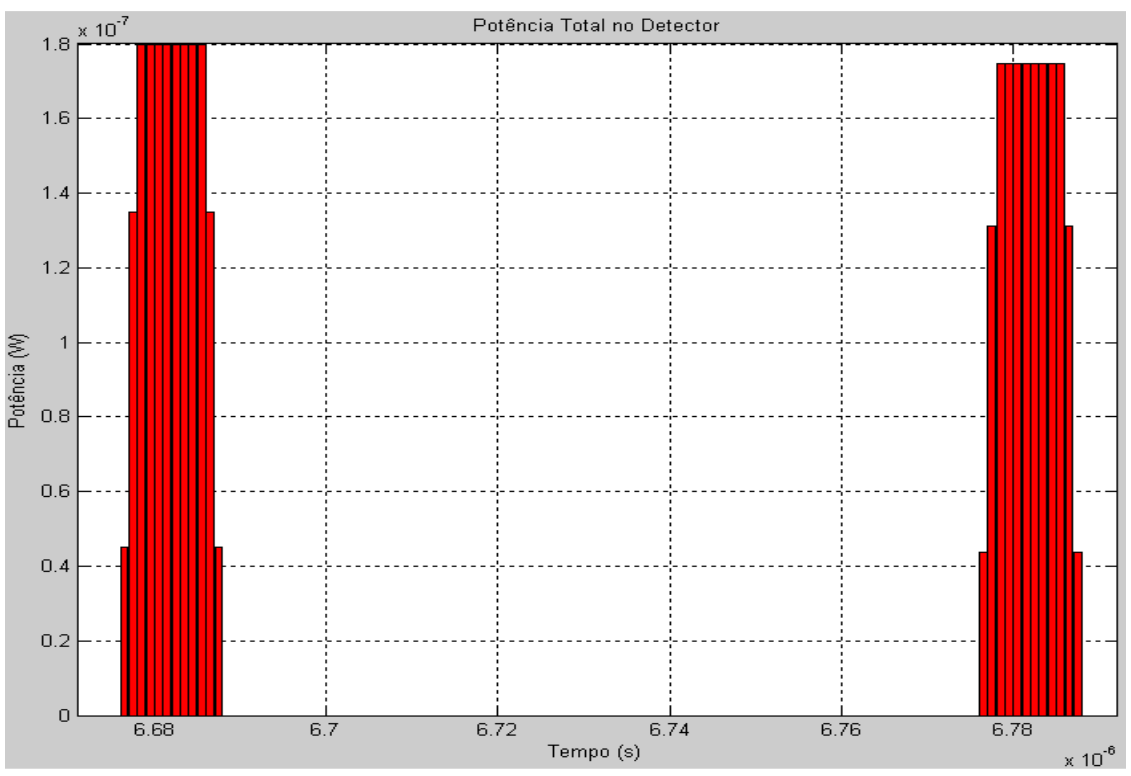

Figura 9 - Forma de onda detectada e amostrada para o caso em que o alvo apresenta desnível de 15 m (falésia central, áreas iguais, inclinação nula, distância: 1000-1015 m).

\section{Conclusões e Comentários}

As curvas obtidas representam o esperado, de acordo com a literatura existente [5], [9].

A distribuição espacial de energia cilíndrica (forma de "chapéu plano") foi utilizada inicialmente. A distribuição gaussiana (mais adequada) será implementada na sequência dos estudos. 
Por causa de sua flexibilidade, a abordagem das "N fontes pontuais", criada para modelagem da luz refletida pelo footprint, permite a inserção de características ainda mais diversas do alvo, além daquelas já consideradas (quatro diferentes alturas, inclinações e refletividades).

As modelagens e simulações efetuadas possibilitaram a compreensão dos detalhes da operação de um altímetro laser pulsado com operação baseada na detecção do tempo de voo, com as características do ALR. Tal compreensão permitiu (e permitirá) a identificação e definição de parâmetros de projeto essenciais à operação que ainda não tenham sido identificados, assim como o refinamento de valores previamente estabelecidos em projeto para alguns parâmetros. Como exemplos, cita-se o tempo de amostragem do sinal detectado (simulações indicam dt=1 nano segundo) e as definições dos tipos de detector e de oscilador a utilizar no aparelho. Estes últimos devem ser adequados para registro da forma de onda retornante esperada (identificada em simulação), com preservação de todas as características relevantes, para extração, via processamento, da informação desejada (com a resolução requerida).

O ambiente de simulação criado será utilizado para inserção e teste de novas rotinas que serão utilizadas na UCPS do ALR, como as rotinas de processamento dos sinais emitidos (diferentes gatilhos para início da contagem do tempo de voo) e recebidos (instante de detecção de um retorno e interpretação do sinal de retorno).

\section{Referências}

[1] Elbert E. N. Macau ; Othon C. Winter ; Haroldo F. Campos Velho; Alexander A. Sukhanov Antônio Gil Vicente de Brum; J. Leonardo Ferreira ; Annibal Hetem; Gilberto M. Sandonato ; Rafael Sfair THE ASTER MISSION: EXPLORING FOR THE FIRST TIME A TRIPLE SYSTEM ASTEROID. Proceedings of the 62nd International Astronautical Congress, Cape Town, 3-7 October 2011. http://www.iafastro.net/iac/archive/browse/IAC-11/B4/2/10263/

[2] BRUM, Antonio Gil Vicente de ; Hetem Jr. Annibal ; REGO, I. da Silveira ; Francisco, Cayo, P. F. ; Fenili, A. ; Madeira, Fernando ; CRUZ, F. C. ; Assafin, Marcelo . Preliminary Development Plan of the ALR, the Laser Rangefinder for the ASTER Deep Space Mission to the 2001 SN263 Asteroid.. Journal of Aerospace Technology and Management, JATM, v. 3, p. 331-338, 2011. doi: 10.5028/jatm.2011.03033611. DOI: 10.5028/jatm.2011.03033611

[3] Gaskell, R. W. Automated landmark identification for spacecraft navigation. 2001 AAS/AIAA Astrodynamic Specialist Conference, Quebec City, Quebec, Canada. 30-Jul-2001. Online at: http://hdl.handle.net/2014/12954

[4]. Gaskell, R. W. Barnoiun-Jha, O. S. and Scheeres, D. J. MODELING EROS WITH STEREOPHOTOCLINOMETRY. Lunar and Planetary Science XXXVIII (2007). Planetary Science Institute. Online at http://www.Ipi.usra.edu/meetings/lpsc2007/pdf/1333.pdf

[5] SHAN, Jie e TOTH, Charles K. Topographic Laser Ranging and Scanning: Principles and Processing. 2009, $590 \mathrm{p}$.

[6] Wehr, Aloysius; Lohr, Uwe. Airborne laser scanning-an introduction and overview. ISPRS Journal of Photogrammetry \& Remote Sensing 54 (1999). P. 68-82. 1999 Elsevier Science. On line in: http://warnercnr.colostate.edu/ lefsky/isprs/1136.pdf.

[7] Kamermann, G.W., 1993. Laser radar. In: Fox, C. S., Ed., Active Electro-Optical Systems, The Infrared and Electro-Optical Systems Handbook. SPIE Optical Engineering Press, Ann Arbor, MI.

[8] Brenner, C. Aerial Laser Scanning. International Summer School on "Digital Recording \& 3D Modeling", Aghios Nikulaos, Crete, Greece, 24-29 April 2006.

[9] Marti, Kilian. The BepiColombo Laser Altimeter - Detector Characterization and Implications for Mercury Science. Bern University.2005. 